\title{
O ARGUMENTO DO CONHECIMENTO DO CRIADOR E A METODOLOGIA PROJETUAL NO CAMPO DO DESIGN
}

\author{
Prof. Dr. Alberto Cipiniuk \\ Pontifícia Universidade Católica do Rio de Janeiro (PUC-Rio) \\ cipiniuk@puc-rio.br \\ MSc. Fabiana Oliveira Heinrich \\ Pontifícia Universidade Católica do Rio de Janeiro (PUC-Rio) \\ Doutoranda - Bolsista CAPES \\ fabianaheinrich@gmail.com \\ MSc. Wilson Silva Prata \\ Pontifícia Universidade Católica do Rio de Janeiro (PUC-Rio) \\ Doutorando - Bolsista FAPEAM \\ wilsonprata@gmail.com
}

Resumo: Neste estudo, buscamos aproximar do campo do Design, que é hegemonicamente pautado pelo fazer, isto é, pela prática, a noção de argumento do conhecimento do criador, tese de que conhecer é ser capaz de criar ou produzir aquilo que se conhece, e suas origens e entendimentos oriundos do Ceticismo Moderno no campo da Filosofia. Ao problematizarmos a noção de metodologia projetual, passo inicial da prática do Design, observamos a repetição da noção de argumento do conhecimento do criador em distintos momentos: primeiramente, nos primórdios da fundação do campo, com a noção e uso da metodologia projetual em Gropius e na Bauhaus; em seguida, com uma reflexão sobre a metodologia projetual no Design a partir de uma conferência do historiador Giulio Argan, relevante teórico dos campos da Arte, Arquitetura e Design.

Palavras-chave: campo do Design, campo da Filosofia, metodologia projetual, ceticismo moderno, argumento do conhecimento do criador.

Abstract: In this study, we aim to connect the Design field, that is hegemonic orientaded by the "make", that is, by a praxis, to the "maker's knowledge" notion, that in which to know something is to be able to create or to produce that which is known, and its origins and understandings from the Modern Ceticism in the Philosophy field. When we put into question the notion of project methodology, the first step in the Design praxis, it's 
possible to perceive the repetition of the maker's knowledge notion in two distinct moments: firstly, in the dawn of the Design field, with the project methology theory and praxis with Gropius and the Bauhaus; and secondly, in a reflexion upon project methodology in a speech given by the historian Giulio Argan, an important theorethician from the Arts, Architecture and Design fields.

Keywords: Design field, Philosophy field, project methodology, modern ceticism, maker's knowledge.

\section{INTRODUÇÃO}

O campo do Design, que começa a se estruturar a partir da Revolução Industrial (século XVIII), face às necessidades históricas desse período e aos adventos tecnológicos que ela trouxe (FORTY, 2007), ainda hoje se apresenta como um campo em formação, complexo e com fronteiras não bem delimitadas. Sua proximidade com outros campos do conhecimento, como as Engenharias, as Artes e a Arquitetura, ajudam-no em algumas de suas conceituações, porém não dão conta de questões relativas à sua ontologia e a seus percursos epistemológicos, históricos e sociais. Deste modo, uma aproximação com o campo da Filosofia apresenta-se como um relevante esforço em tentar - se não delimitar, ao menos clarificar, revisitar - algumas das conceituações e limites fronteiriços já existentes, contudo ambíguos; primando assim por um melhor entendimento da configuração histórico-contemporânea do campo investigado.

Com efeito, ao aproximarmos a noção do fazer, da prática, da metodologia projetual, hegemônica no campo do Design, à noção de argumento do conhecimento do criador, tese de que conhecer é ser capaz de criar ou produzir aquilo que se conhece, oriunda do pensamento cético moderno da Filosofia; tentamos problematizar e ao mesmo tempo elucidar o conceito e a posição da atividade projetual no campo do Design. Para tal, partimos de referências no campo da Filosofia apresentadas na disciplina Tópicos Especiais em História da Filosofia, ministrada pelo Prof. Dr. Danilo Marcondes no Programa de Pós-Graduação em Filosofia da PUC-Rio no primeiro semestre do ano de 2012 e de artigos e autores por ele indicados, que discorrem sobre a temática do Ceticismo Moderno; e, no campo do Design, de dois distintos textos do historiador Giulio Argan, que tratam da temática projetual em diferentes contextos temporais: um, sobre os primórdios da configuração do campo do Design, a partir de feitos e escritos do arquiteto e designer Walter Gropius e da Escola Bauhaus; e outro, sobre a questão histórica projetual já na década de 1980.

Assim, ao beirarmos esta aproximação, procuramos desvelar a posição de destaque do "fazer" metodológico no contexto histórico-contemporâneo do campo do Design e seus possíveis desdobramentos teórico-práticos tanto positivos quanto negativos, pois tal elucidação faz-se necessária na busca por um melhor entendimento do campo.

\section{A NOÇÃO DE ARGUMENTO DO CONHECIMENTO DO CRIADOR}

A noção de conhecimento nem sempre foi concebida conforme hoje a compreendemos. O argumento do conhecimento do criador (maker's knowledge), ou 
seja, a tese de que conhecer é ser capaz de criar ou produzir aquilo que se conhece, é entendido como característico da nova concepção de Ciência - a scientia activa, prática ou aplicada - que emerge no contexto da Revolução Científica Moderna. Essa visão sobrepôs-se à visão grega, dominante até então, na qual se concebia conhecimento como algo metafísico, ao alcance somente daqueles que eram capazes de reconhecer a essência das coisas.

Conforme supracitado, na visão grega, o conhecimento superior era o conhecimento metafísico, que como o próprio nome diz, consistia em entender o porquê (causa final) de determinado produto ou ideia, a razão além do material (causa eficiente); de modo que o conhecimento do criador - o fazer, a prática - era visto como uma forma inferior de conhecimento (techne) em oposição ao conhecimento contemplativo (episteme), teoria em que a verdade é apreendida, não criada. Com um mundo estático, ordenado, imaginava-se que era possível compreender o cosmos e as coisas que nele existem desde que se entendessem seus princípios, ou seja, conhecendo a essência das coisas - em terminologia aristotélica, a causa final determina a causa eficiente. Por essa razão, o conhecimento do criador era considerado limitado por estar condicionado a diversas restrições como a técnica do artífice, as ferramentas, o material e em última instância, a avaliação de quem iria usar aquele produto (MARCONDES, 2007).

Entretanto, conforme também já mencionado, estas concepções não mantiveram-se perenes: o enfraquecimento gradual destas certezas veio a ocorrer na Idade Moderna, a partir do século XV, quando foram desvendados os erros dos antigos. Conforme aponta Marcondes (2007), o abandono de vários pressupostos estabelecidos no período medieval deu-se em virtude de quatro fatores-chave: 0 humanismo renascentista, a descoberta do Novo Mundo, a Reforma Protestante e a Revolução Científica.

Assim, apontamos que o termo Renascimento foi primeiramente utilizado para designar o estilo de pintura que, no século XIV, rompe com a arte gótica e retoma o estilo clássico. A valorização dos clássicos ocorria não só nas Artes, mas também na Filosofia, que, à exemplo da pintura, quebra com o estilo adotado até então, a escolástica medieval, e passa a adotar princípios do humanismo greco-romano como base da sua identidade cultural. Com efeito, um traço representativo dessa mudança foi a forma como o homem se via ou representava: anteriormente, preponderava 0 tema medieval da miseria hominis (a miséria do homem), no qual os principais valores eram o sofrimento humano, o sobrenatural, a vida contemplativa, a sorte e a fé. No Renascimento, esse tema é substituído pela dignitas hominis (a dignidade do homem), no qual passou a imperar o valor das letras, das conquistas, da vida ativa, da virtude e da razão.

A Reforma Protestante, por sua vez, foi pertinente por dois aspectos: o primeiro, quanto ao descrédito da Igreja Católica enquanto autoridade religiosa e representante da vontade Deus, o qual se deve em grande parte aos inúmeros conflitos político e econômicos envolvendo a Igreja; e o segundo, que consiste no desenvolvimento de uma ética que valorizava a consciência e liberdade individual como lugar da certeza, e que assim possibilitava o acúmulo de capital, permitindo o surgimento de uma classe burguesa.

Já a descoberta do Novo Mundo, esse novo continente, formado pelas Américas, ajudou na concepção do descrédito das tradições, pois além destas jamais 
terem mencionado tamanha massa de terra, suas teorias não conseguiam abarcar as exóticas manifestações culturais e mesmo as naturais ali encontradas. Com a impossibilidade de se encaixar essa "nova" realidade aos conhecimentos de Geografia e Astronomia dominantes, o mundo ordenado, sublunar pitagórico, ruiu de vez; já que mesmo os céus eram diferentes nesse novo mundo. A Natureza era distorcida aos olhos dos desbravadores: plantas e rios que pareciam fora de escala, aves de todas as cores, cobras venenosas, além do calor e da umidade excessivos para os padrões europeus. Logo, nesse Novo Mundo, boa parte do conhecimento acumulado até então se mostrava inútil.

Por fim, a Revolução Científica veio demonstrar o erro na concepção do próprio cosmo: a partir das teorias de Copérnico, provou-se que o modelo do universo geocêntrico era equivocado, e isso levou à substituição deste pelo modelo heliocêntrico. Essa mudança é representativa do abandono do modelo de conhecimento estabelecido pelos gregos, o da indução; por aquele que vai caracterizar a forma de conhecimento da modernidade, o método hipotético-dedutivo. Assim, abandona-se a ciência contemplativa por uma ciência ativa, em que o conhecimento apresenta-se em bases dinâmicas e cambiáveis.

Deste modo, observamos como essas transições levaram os pensadores à época a uma reavaliação da forma de se conhecer o mundo, e mesmo do quanto deste podemos realmente conhecer, conforme ilustra Marcondes (2012):

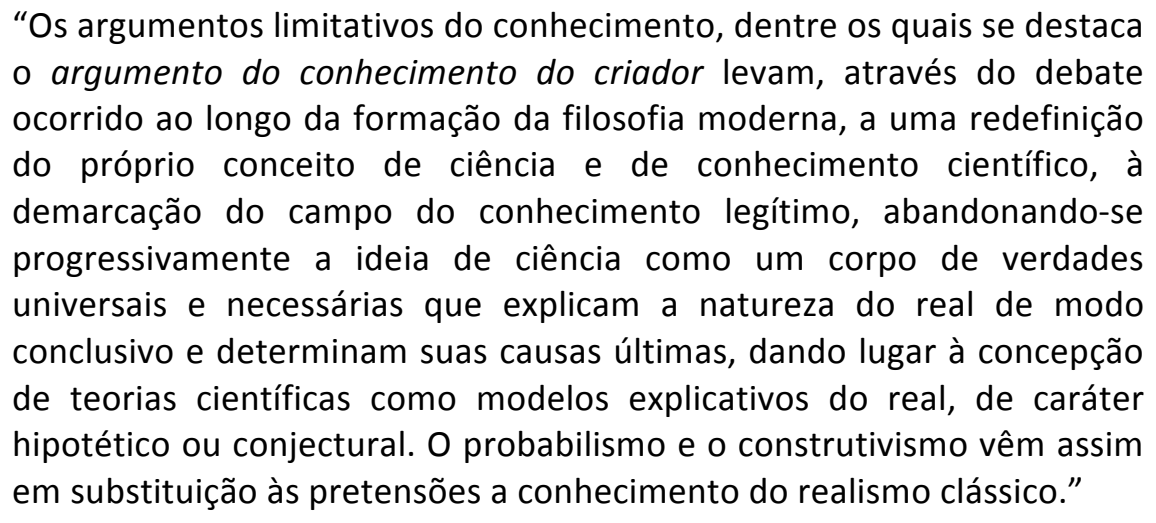

Além da percepção destas mudanças, os céticos vão defender que os antigos erraram por terem usado mal sua razão. Logo, para não cair em erro novamente, aponta-se que devemos submeter todas as teorias ao crivo da razão, duvidando de toda e qualquer pretensão de verdade. Pode-se observar, portanto, que esse processo tentou imunizar o filósofo das ideias ruins, além de levar a ciência a abandonar o método analógico (indutivo), que rui por afirmar que pode-se conhecer o novo a partir do antigo. Assim, abre-se uma oportunidade para um elemento chave na ciência moderna, o conhecimento empírico. A dúvida torna-se, então, um instrumento do processo metodológico de descoberta da verdade.

Dessa maneira, passa-se a aceitar, na Filosofia Moderna, a concepção de que conhecer é criar, fazer, produzir (MARCONDES, 2007): inverte-se, portanto, o valor da teoria e da prática, sendo a teoria preterida pela prática. Um dos principais filósofos para o estabelecimento dessa concepção foi Giambattista Vico, e é dele um dos termos mais representativos dessa nova ciência, Verum Factum. ${ }^{1}$ Sua obra Nova

\footnotetext{
${ }^{1}$ Verum Factum: termo em latim que pode ser entendido como "o verdadeiro é o que é feito" ou "a verdade é o que se constrói".
} 
Ciência é um exemplo das mudanças decorrentes da Revolução Científica, quando foram lançados os postulados da ciência moderna na qual separa-se a questão metafísica da episteme. Nessa visão, reconhece-se que o homem só pode conhecer aquilo que cria. Assim, por não ter criado a natureza, o homem não teria acesso a esta - logo, não poderia conhecê-la. Entretanto, apesar de não a ter criado, o homem pode imitá-la e reproduzi-la através da técnica; e essa nova forma de lidar com o real acaba por abalar os pressupostos metafísicos assim como seu realismo ontológico e epistemológico.

Com efeito, é com a mudança do caráter estático e ordenado da instância metafísica para a dinâmica e pluralidade das novas ciências que a noção de conhecimento diferencia-se e influencia a toda a concepção de construção e ordenação do pensamento, do ensino e da prática humana. Ao considerar o ato de criar como uma forma legítima de conhecimento, o agente e seu contexto passam para o centro dessa dinâmica e assim, afasta-se deste centro a noção romântica de uma verdade universal. Logo, é neste momento que se reconhece e se aceita o conhecimento como limitado (MARCONDES, 2007), e começa-se a repensar e reestruturar as disciplinas do conhecimento humano até então existentes. A grande questão torna-se, então, a aplicabilidade do conhecimento, e o foco passa da teoria para a prática.

Em uma breve retomada, voltamos à Antiguidade para entender o sentido dado ao termo conhecer: este era crido como a compreensão das causas - conhecer significava compreender os fenômenos e efeitos de uma causa. Dentre essas, temos: causas formais (o quê?), materiais (de quê?), eficientes (como?) e finais (para quê?). Segundo Aristóteles, a causa final era a mais importante, pois conhecer a finalidade de uma ação ou objeto configurava seu real entendimento. Entretanto, para a Modernidade, a causa mais importante tornava-se outra: a causa eficiente toma a frente, pois ela era a causa do criador, aquela que demonstra o que ele sabe fazer e, portanto, o que ele conhece. Consequentemente, este será o critério para estabelecimento de qualidade; e assim o conceito do que é possível conhecer, do conhecimento do criador, é alterado, incorporando à causa eficiente do artífice e à causa final do usuário a causa formal daquele que concebe a ação. Com isso, o ato de criar passa a ser entendido a partir de uma relação direta entre causa formal e causa eficiente (MARCONDES, 2007).

Por fim, podemos observar na Modernidade que: a causa formal vai ser problematizada, a causa material vai ser trabalhada e pouquíssima atenção será dada a causa final. A ciência moderna passa, portanto, a destacar o papel do argumento do conhecimento do criador, incorporando postulados que podem ser considerados céticos, tais como: 1) conhecer é equivalente a fazer, produzir, ou criar; 2) só podemos conhecer aquilo que fazemos, produzimos, ou criamos; 3 ) o conhecimento pressupõe a capacidade de entendimento do processo causal de modo que aquele que conhece a causa pode produzir o efeito esperado (causalidade eficiente); 4) o conhecimento é sempre do fenômeno, uma vez que a essência, a "real natureza das coisas" se encontra além de nosso modo de apreensão, já que o ser humano não cria a realidade; e 5) o conhecimento científico define-se como técnico ou aplicado sendo o seu resultado, ou sucesso, a medida de sua validade. 


\section{GROPIUS E A METODOLOGIA PROJETUAL}

Conforme supracitado, é a partir da Filosofia Moderna, mais precisamente nos séculos $X V$ e XVI, que o ser humano começa a tentar compreender o mundo através da razão. A organização de conhecimento específico oriunda desta prática, também chamada de disciplina, tem seu aprofundamento com a chegada da Revolução Industrial. Esta, na busca por uma ciência absoluta, de maneira estruturalista categoriza o conhecimento à procura de maior eficiência e eficácia. Em consequência disto, as diferentes ciências - naturais e humanas - organizam os estudos de acordo com a sua especificidade. Logo, temos os limites de específicos conhecimentos demarcados pelo seu objeto de estudo, porém, quando necessário, buscam-se ampliações ou outros conhecimentos em outras áreas e disciplinas. Assim, estas ciências - que se constituíram de acordo com as características e contextos de seus períodos históricos -, não podem ser consideradas estanques: elas são construídas a partir do seu tempo e da relação com a sociedade.

Consequentemente, é a partir do século XX e de novas formas de conceber 0 conhecimento que a especialização, que antes se limitava a algumas disciplinas, passa a se apresentar como uma possibilidade de, ao mesmo tempo, ampliação e especificação, categorização de conhecimento. O campo do Design, formado a partir da Revolução Industrial, insere-se nesta lógica de especialização e categorização do conhecimento, conforme já explicitado. Entretanto, para uma melhor compreensão das variáveis e consequências do surgimento deste novo campo, torna-se importante entender os eventos que se relacionam a ele.

Um dos fatores de principal importância para o surgimento do campo do Design foi o estabelecimento da lógica econômica de mercado capitalista e do modo de produção industrial como determinantes da política dos países influentes à época. Conforme Argan (2010) aponta, enxerga-se no aparato industrial a promessa de uma sociedade nova, capaz de criar riqueza, bem-estar, harmonia entre as potencias e entre todos os povos; porém, conforme também posto pelo autor, o capitalismo industrial acaba por suscitar conflitos entre grandes potências e entre classes sociais.

Em adição a esta configuração socioeconômica, Argan (2010) também menciona a relevância de influências do campo filosófico, no qual o tema dominante à época é o do estranhamento, da alienação, da perda de identidade do indivíduo na sociedade e do enrijecimento da sociedade na indistinção da massa. É nesta época que surgem os chamados mestres da suspeitas ${ }^{2}$ (Freud, Marx e Nietzsche) e a noção de subjetividade, abrindo espaço para novas percepções acerca da realidade e da sociedade. Ainda, na política, as lutas pelo poder apresentam-se como predominantemente dominadas por partidos, que geralmente possuem agendas ideológicas opostas umas a outras, pensamentos de esquerda ou de direita configurações que acabam por caracterizar a noção de ideologia como uma imagem da sociedade como se queria que esta fosse, na qual partidos constitui-se de um conjunto de pessoas que professam os mesmos ideais e se associam com a intenção de fazê-los triunfar e de conquistar o poder.

${ }^{2}$ Essa definição é dada posteriormente pelo filósofo francês Paul Ricoeur (1913-2005) para os pensadores Marx, Nietzsche e Freud. Ele assim os apresenta, pois entende que são esses três que primeiramente lançaram as suspeitas sobre o processo supostamente lógico de formação da consciência. 
Por conseguinte, além do cenário econômico, político e filosófico, não se pode ignorar a crise da Arte na Europa e as mudanças ocorridas nesse campo; mudanças essas não apenas de caráter técnico, mas principalmente ideológico. Deste modo, observando o campo da Arte no período de 1880 a 1940, podemos dividir a arte europeia em quatro períodos de acordo com Argan (2010):

a) 1880 - 1908: fase do Modernismo, na qual, afirma-se a finalidade social da Arte com acentos semelhantes aos do socialismo humanitário - pretende-se que na arte se realize uma renovação profunda, como a que a indústria realizou no campo da produção. Logo, o caminho iniciado pelos impressionistas depois de 1860, passando pelos diversos estilos subsequentes, desdobra-se em dois laboratórios: a matriz clássica francesa e a matriz romântica alemã;

b) 1908 - 1918: observa-se uma transformação radical no campo artístico, uma arte voltada à expressão do sujeito moderno e já completamente livre do realismo. Com o Blaue Reiter; se inicia a arte que será chamada de não figurativa ou abstrata;

c) 1918 - 1930: na fase do pós-guerra, a Arte move-se em três direções: Construtivismo (engajamento na construção de uma nova sociedade onde os erros recentes não se repitam); Surrealismo (distanciamento da realidade, arte como uma aventura interior) e Dadaísmo (recusa total da sociedade de seus valores e da arte como valor social). No momento, entretanto, nos interessa o primeiro direcionamento, o Construtivismo, pois foi deste que se desdobrou as correntes de pensamento mais dominantes no campo da Arquitetura e, por consequência, também no campo do Design;

d) 1930 - 1940: observa-se uma crise cultural, que acabaria por explodir com a Segunda Guerra Mundial, com a condenação e persecução da arte moderna em todos os regimes totalitários.

Assim, nota-se que na primeira metade do século, a arte europeia adquire um diferente grau de importância: com o Impressionismo e o Simbolismo, a Arte já não é considerada algo que se produz sob encomenda - ela é, na verdade, produto de uma pesquisa autônoma do artista, de uma indagação e motivação própria. Assim, conforme Argan (2010) aponta, com o Impressionismo, a Arte acaba por impor-se como uma pesquisa disciplinar autônoma, na qual os artistas adquirem consciência de que ela não pode interessar apenas às classes ricas, mas sim a todas as instâncias, todos os extratos sociais de uma sociedade.

Com efeito, esse pensamento ecoou na produção industrial com o Art Nouveau (1890-910), estilo que se propõe como o resgate do lado artístico nessas produções. Suas formas orgânicas aludem à natureza elaborada, refinada. Aqui, o belo está além do conveniente. Entretanto, a essa linha de pensamento vai se opor, conforme Argan (2010), através das correntes racionalistas e construtivas, a noção do útil ou funcional, que acaba por ser em si também belo, porque todo produto comunica uma informação e, só quando esta for essencial e não redundante, haverá valor estético. Observamos, portanto, que a utilidade ou a funcionalidade acaba por tornar-se critério de beleza, e, consequentemente, também critério de valor estético.

Ainda nesse período, as Artes Aplicadas, as atividades artesanais, são consideradas como inferiores às Belas Artes (ARGAN, 2010). Contudo, com o avanço da indústria e sendo esta parte importante da agenda política e econômica de vários países, torna-se necessária uma forma de produção industrial que operacionalize a fabricação de mercadorias com algum apelo estético, mas sobretudo dessa "nova" 
estética de caráter funcional. As tentativas anteriores, tal como Art Nouveau e Arts and Crafts, não conseguiram desenvolver uma metodologia que equacionasse bem o problema das Artes Aplicadas com as Belas Artes. Logo, foi frente a esse desafio que Gropius unificou as duas visões e, com o apoio de colegas arquitetos e de um grupo de artistas de vanguarda, fundou Das Staatliche Bauhaus ${ }^{3}$, com uma proposta e um método de ensino revolucionários, a partir dos quais surgiu o Design Moderno. Com uma visão mais funcionalista, a Werkbund ${ }^{4}$ alemã acabou por afirmar a necessidade de adequação da ideação artística às possibilidades do meio mecânico, ou seja, o programa orgânico da Bauhaus, para o qual a funcionalidade determina a forma.

Dessa maneira, conforme Argan (2010) argumentava, a busca de uma relação orgânica ou tátil, e não mais apenas de colaboração, entre o momento ideativo (ou criativo) e o momento operativo determina após 1920 a formação de um "estilo" caracterizado pela nudez funcional das arquiteturas e dos objetos e pela "racionalidade" da correspondência dos objetos a seu uso prático: o estilo 'standard', como forma perfeita realizável nas condições técnicas e econômicas presentes. 0 standard de um objeto, ainda segundo o autor, é o produto da crítica aos tipos anteriores do mesmo objeto e, ao mesmo tempo, o projeto de um novo modelo, que por sua vez será logo superado pela crítica e pela projetação de um modelo ainda mais novo.

Assim, para chegar a esse resultado, Gropius assume a racionalidade como um método, o qual permite localizar e resolver os problemas apresentados pela existência continuamente. Gropius acompanha a revolução ocorrida na arte europeia da primeira metade do século XX e rompe com a satisfeita figuração; e a exemplo da didática expressionista, na sua metodologia a fórmula assume força libertária. Para ele, a racionalidade e o método são formas de solucionar os problemas, não são as respostas em si: a resposta irá surgir da própria ordenação do processo criativo. Dessa didática resultaria uma arte inteiramente técnica, supostamente livre de toda ideologia. Com efeito, para estabelecimento da função social desse "novo artista", algumas instâncias sociais iriam ser redefinidas, outras eliminadas e outras absorvidas: a indústria era o local onde este iria operar a libertação de toda sociedade.

No método proposto por Gropius, não há espaço para o gênio carismático nem para a arte transcendente. A arte deve obedecer a um funcionalismo estrito, é resultado de um método racional, a techne acordada coletivamente que liquida qualquer poiesis. Logo, através dessa abordagem, Gropius pretendia projetar para uma sociedade sem classes. Sua metodologia, ideologia e abordagem procuravam, através do Design, revelar a contradição entre pragmatismo e racionalismo. Conforme Argan (2010), o tecnicismo de Gropius poderia, a rigor, ser interpretado como uma nãopolítica, no sentido que visa resolver ou até evitar, pela lúcida funcionalidade social, todo embate ideológico. Gropius tentava olhar o futuro, guiar a sociedade através do produto industrializado, e com essa forma nova de projetar, encerrar os conflitos e a desigualdade.

\footnotetext{
${ }^{3}$ Em alemão: casa estatal de construção.

${ }^{4}$ A Deutscher Werkbund (ou "Federação Alemã do Trabalho") foi fundada em 1907, por um grupo de arquitetos, designers e empresários alemães que tinham estado, de alguma maneira, ligados ao Jugendstil, ou "Arte Nova Alemã". Entre seus principais expoentes encontra-se Peter Behrens, Walter Gropius e Mies Van der Rohe.
} 


\section{ARGAN E A METODOLOGIA PROJETUAL}

Em um salto temporal, já na década de 1980, continuamos a identificar pressupostos céticos na questão metodológica do campo do Design. Em conferência proferida ao Departamento de Arquitetura da E.P.F.L. (École Polytechnique Fédérale de Lausanne), no dia 25 de maio de 1983, Giulio Argan discorreu sobre a história da metodologia do projeto. Não obstante a fala tenha sido proferida dentro de um departamento de Arquitetura, julgamos a transcrição desta (publicada em 1992 pela revista Caramelo, FAU/USP) válida também para o campo do Design, face à sua proximidade à questão projetual; e a utilizamos, deste modo, para fins de problematização e esclarecimento da questão do maker's knowlegde e da metodologia projetual no campo do Design debatida neste artigo.

Na referida fala, Argan (1992) inicia sua discussão afirmando que a atividade projetual é uma atividade presente em todas as artes, pois o desenho, o projeto, constitui-se da relação direta entre uma atividade puramente intelectual e uma atividade manual, uma atividade ao mesmo tempo individual e coletiva. Ainda, o autor considera o projeto como "já uma imagem realizada, (...) uma imagem feita visando uma execução técnica" (ARGAN, 1992), e que, por isso, não existe a possibilidade de uma desvinculação do real com o imaginário, ou seja, do fazer com o saber, pensar. Conforme o pressuposto cético de que conhecer é fazer, produzir ou criar (MARCONDES, 2007), já podemos identificar aqui o fazer enquanto peça-chave do campo do Design.

Entretanto, a noção de que a atividade projetual está presente em todas as artes nem sempre foi desta maneira concebida. Enquanto atualmente pensa-se na atividade projetual como "fundamental, estrutural para toda a atividade humana" (ARGAN, 1992), anteriormente à cultura humanista esta configuração não se sustentava de tal forma, sendo a questão projetual relegada a um segundo plano em decorrência da inferioridade do fazer técnico. Assim, é a partir de uma dita civilização do projeto (ARGAN, 1992), do enaltecimento do modo de fazer, que a atividade projetual toma importância e, consequentemente, louva os pressupostos céticos do argumento do conhecimento do criador enquanto forma de conhecimento superior, em detrimento do conhecimento teórico.

Além disso, o autor discorre sobre as diferenças entre o que podemos considerar a cultura ${ }^{5}$ do projeto e a cultura do modelo, nas quais as noções de reprodução, imitação, e criação aparecem. Conforme menciona o autor, a cultura dos projetos veio depois de um outro tipo de cultura, que era uma cultura do modelo; e há uma diferença notável entre a ideia de projeto e a ideia de modelo. Enquanto um modelo pode apenas ser imitado e a atividade que imita é uma atividade de reprodução, é uma atividade de reflexão; podemos ter, por outro lado, uma cultura que é transgressão, e transgressão de si mesma. Com efeito, pode-se bem dizer que a cultura do projeto representa "(...) o fim de uma concepção de arte como imitação, como mímesis" (ARGAN, 1992).

Esta consideração vai também ao encontro de um pressuposto cético, aquele da reprodução e imitação como formas de conhecimento. Não obstante Argan apresente-a, neste momento, como inferior à criação tida como "pura", a cultura do

\footnotetext{
${ }^{5}$ Fazemos uma ressalva ao uso do termo cultura nesta conceituação, pois por cultura entendemos um conjunto de práticas e convenções, e não apenas um modus faciendi.
} 
modelo foi essencial para a transposição da superioridade do conhecimento metafísico, teórico, para o conhecimento técnico.

Ainda, ao discorrer sobre a questão temporal do fazer, o autor afirma que todo projetar é um ato contínuo, e que este, consequentemente, acaba por gerar novas atribuições de valor, valores estes de ordem econômica, política e social (ARGAN, 1992). Entretanto, tal configuração acaba por gerar também problemas de método e de critério, pois as fronteiras dos aspectos a serem considerados ou desconsiderados tornam-se evanescentes, ao contrário da cultura do modelo, na qual a reprodução do modelo consagrado é o critério de valor para avaliação da técnica executada. Como o próprio autor afirma:

"O projeto é exercer sempre uma crítica sobre a existência; e supor qualquer coisa de diferente e evidentemente melhor. Eis porque se pode muito bem dizer que todo o projeto pressupõe uma ideia de valor. (...) Se colocamos uma ideia de valor como meta à qual queremos atender, então está claro que não podemos conceber o projeto sem uma finalidade. (...) 0 projeto procura realizar o valor dentro do horizonte da existência e não além deste. (...) O valor não é algo que está ligado às coisas, mas uma atribuição de significação que se dá às coisas" (ARGAN, 1992).

Destarte, o autor discorre sobre a necessidade de proximidade do fazer com o contexto, com a configuração contemporânea do desenvolvimento do projeto, pois este não pode ser tomado isoladamente, nem quanto à sua significação, nem quanto à sua relevância. $\mathrm{O}$ autor afirma que:

"Se queremos fazer projetos que sejam coerentes com a ideia de história, de crítica, estas sendo ideias estruturais da cultura contemporânea, o primeiro passo é reconhecer as contradições da sociedade na qual vivemos. (...) Evidentemente as condições de equilíbrio não são eternas, e eis porque estas não se realizam, mas é sempre possível procurar realizar uma eliminação das contradições. (...) É por isso que o projeto não pode ser tão simplesmente um exame dos dados objetivos e um cálculo das resistências dos materiais ou do preço dos materiais em relação à disponibilidade financeira, mas um fator de intervenção ativa na realidade para resolver as contradições existentes" (ARGAN, 1992).

Logo, o ato de projetar no campo do Design deve considerar o contexto em que determinado projeto está inserido, em conformidade com o dito anteriormente, porém, além disto, deve considerar que as condições de equilíbrio, ou seja, que este contexto que parece ser favorável ao desenvolvimento do projeto não é eterno. Deste modo, devem-se considerar aspectos das mais diversas naturezas ao se utilizar uma metodologia projetual no campo do Design, pois fatores econômicos, políticos e sociais que certamente virão a mudar estarão em jogo. Assim, torna-se evidente que a falta de equilíbrio pode ser um ponto tanto positivo quanto negativo (positivo: novos desafios; negativo: não é o Design que os resolve), afinal não temos como intervir efetivamente em todos os aspectos da sociedade, isto é, nos aspectos extra-projetuais que nos circundam. 


\section{CONCLUSÃO}

Assim, é a partir das aproximações traçadas entre as noções de argumento do conhecimento do criador do campo da Filosofia e de metodologia projetual do campo do Design, que pudemos observar que os pressupostos céticos fazem-se presentes na questão projetual do campo do Design tanto temporalmente quanto conceitualmente.

Ao apercebermo-nos da dinâmica evolucionária de caráter circular dos argumentos utilizados e da constante mudança dos critérios, pudemos compreender a posição de relevância do fazer pautada pelas tecnologias vigentes e pelo teor prático, pouco reflexivo da práxis no campo do Design face à sua condição econômica, mercadológica e política; o fazer, isto é, a metodologia projetual é legitimada como um dos nortes do campo, um dos meios de conceituação e limitação de fronteiras, pois sua flexibilidade conceitual e de utilização permite que esta se modifique de acordo com as novas configurações de necessidades que surgem neste campo.

Também, ao observarmos a latente ressignificação da noção de criatividade e revalorização dos produtos, principalmente a partir da esfera social, constantemente mutante, torna-se evidente que a relevância posta nos processos de feitura, ou seja, no uso de uma metodologia projetual para o desenvolvimento de novas maneiras de pensar e produzir bens simbólicos tome proporções conceituais do campo, pois este prima por soluções "originais" e por conhecimento "inovador". Não obstante tais termos tenham procedência e uso questionáveis, são eles que, hoje, comandam os rumos do campo do Design. Assim, ao nos conscientizarmos de que os atuais "novos processos" ou "novos conceitos" não passam de "reafirmações" de algo anteriormente já existente, acabamos por colimar o processo circular cético supracitado e confirmar que não somente a problemática metodológica do campo do Design, mas também sua problemática conceitual; nunca se esgotarão, pois as já citadas condições de equilíbrio sempre desestabilizarão a balança teórico-prática do campo em questão.

Por fim, é ao percebermos esta constante e crescente consciência de soluções não-definitivas e a contínua problematização da metodologia e da realidade, face ao surgimento exponencial de novos métodos de acordo com novas tecnologias disponíveis ou necessidades "identificadas", que pudemos apreender que os valores que regem o campo mudam e continuarão a mudar, e que tentar buscar uma constante de entendimento talvez não seja um aspecto relevante, mas sim utópico. Não obstante ambas as noções tenham sido de caráter emancipador durante o período histórico de criação da Bauhaus, por si só não conseguiram resolver a problemática da produção do sentido, como Gropius achava que tinha feito - e tal problema não se resolverá, pois produção de sentido do objeto ocorre em parte na produção, mas também na circulação e no consumo; e esse uso se dá em um meio social, que é mutante e mutável. Sendo assim, nunca a instância de produção conseguirá determinar a priori o sentido do objeto, entretanto, o fazer só é possível em um meio social. Estando o agente inserido nesse meio, ele pode utilizar seu repertório de experiência, o domínio de determinados códigos técnicos e sociais para potencializar a eficiência desse fazer, ainda que momentaneamente.

Logo, embora o fazer, a metodologia projetual tenha sido legitimada como norte do campo desde suas primeiras configurações, são as mutações deste fazer e de seu contexto econômico, educacional, político e social, algumas visíveis e explicadas, outras não tão visíveis e veladas, que constituem o seu corpus teórico-prático e que 
permitem a sua constante flexibilização e impossibilidade de fechamento de fronteiras.

\section{REFERÊNCIAS}

ARGAN, Giulio Carlo. A Arte Moderna na Europa: de Hogarth a Picasso. Tradução, notas e posfácio: Lorenzo Mammi. São Paulo: Companhia das Letras, 2010.

ARGAN, Giulio Carlo. A História na Metodologia do Projeto in Revista Caramelo, $n^{\circ} .6$, FAU/USP, 1992.

FORTY, Adrian. Objetos de Desejo: Design e Sociedade desde 1750. São Paulo: Cosac Naify, 2007.

MARCONDES, Danilo. Iniciação à História da Filosofia: dos pré-socráticos a Wittgenstein. Rio de Janeiro: Zahar, 2007.

MARCONDES, Danilo. O Argumento do Conhecimento do Criador como argumento cético in Revista Sképsis. ISSN 1981-4194, ano I, n. 2, 2007.

MARCONDES, Danilo. O Argumento do Conhecimento do Criador e o Ceticismo Moderno. Disponível na internet por http em: <http://www.dbd.pucrio.br/depto_filosofia/99_souzafilho.pdf>. Acesso em 15 Junho 2012. 